\title{
Liver Multiacinar Regenerative Nodules: Imaging Findings and Clinical Implications
}

\author{
Nódulos Regenerativos Multiacinares do Fígado: \\ Achados Imagiológicos e Implicações Clínicas
}

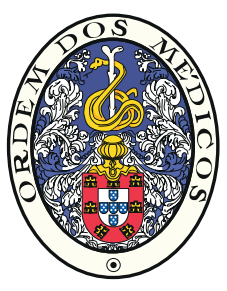

\author{
Henrique DONATO $\rrbracket^{1}$, Luísa ANDRADE¹, Nina BASTATI², Augusta CIPRIANO³, Ahmed BA-SSALAMAH², \\ Filipe CASEIRO-ALVES ${ }^{1}$ \\ Acta Med Port 2018 Sep;31(9):470-477 • https://doi.org/10.20344/amp.10259
}

\section{ABSTRACT}

Introduction: Multiacinar regenerative nodules are benign hepatocellular nodules related to vascular disturbances of the liver. They strongly resemble conventional focal nodular hyperplasia but are connected to different clinical settings, typically chronic liver disease. The purpose of the present study was to describe the key imaging features of these lesions and compare them with a control arm of focal nodular hyperplasia.

Material and Methods: A blinded consensus review of liver magnetic resonance consisting of 26 cases of multiacinar regenerative nodules and 25 cases of focal nodular hyperplasia was performed. Lesion size, shape, margins, structure, T1 and T2 signal intensity, diffusion and contrast-enhanced features (including hepatobiliary phase), presence of a central scar and of a peripheral hypointense rim were compared between the two groups.

Results: Significant differences between multiacinar regenerative nodules and focal nodular hyperplasia included size (median 2.35 cm, IQR: 2.13 , vs $6.00 \mathrm{~cm}$, IQR: 5.20 , respectively, $p<0.001)$, presence of a peripheral hypointense rim after contrast $(\mathrm{n}=9 \mathrm{vs} \mathrm{n}=2$ cases, $p=0.038$ ) and of a central scar $(n=9 v s n=20, p=0.002)$. There were no other significant differences.

Discussion: Overall multiacinar regenerative nodules and focal nodular hyperplasia have very similar imaging features but lack of a central scar and presence of a hypointense rim should suggest a diagnosis of multiacinar regenerative nodules.

Conclusions: Recognition of the imaging findings of multiacinar regenerative nodules can explain some atypical cases of focal nodular hyperplasia, avoiding unnecessary biopsies. They may also be the trigger to investigate an unsuspected underlying liver vascular abnormality.

Keywords: Chemical and Drug Induced Liver Injury; Focal Nodular Hyperplasia; Liver Diseases; Liver Neoplasms; Liver Regeneration; Magnetic Resonance Imaging

\section{RESUMO}

Introdução: Nódulos regenerativos multiacinares são nódulos hepatocelulares benignos relacionados com alterações vasculares hepáticas. São muito semelhantes à hiperplasia nodular focal mas ocorrem num contexto diferente de doença hepática crónica. $O$ objectivo deste trabalho foi descrever os achados imagiológicos principais destes nódulos e compará-los com um grupo controlo de hiperplasia nodular focal.

Material e Métodos: Foi efectuada uma revisão cega de estudos por ressonância magnética de 26 casos de nódulos regenerativos multiacinares e 25 de hiperplasia nodular focal, sendo os dois grupos comparados quanto à dimensão das lesões, morfologia, margens, estrutura, aspecto em T1, T2, difusão e após contraste (incluindo na fase hepatobiliar), presença de cicatriz central e halo hipointenso. Resultados: Foram encontradas diferenças significativas entre nódulos regenerativos multiacinares e hiperplasia nodular focal quanto às dimensões das lesões (mediana 2,35 cm AIQ: 2,13 vs 6,00 cm AIQ: 5,20 respectivamente, $p<0,001$ ), presença de halo hipointenso após contraste ( $\mathrm{n}=9$ vs $\mathrm{n}=2, p=0,038)$ e de cicatriz central $(\mathrm{n}=9$ vs $\mathrm{n}=20, p=0,002)$. Não se observaram outras diferenças significativas.

Discussão: Nódulos regenerativos multiacinares e hiperplasia nodular focal são globalmente muito semelhantes mas a ausência de cicatriz central e a presença de halo hipointenso deve sugerir o diagnóstico de nódulos regenerativos multiacinares.

Conclusão: O reconhecimento dos achados imagiológicos de nódulos regenerativos multiacinares pode explicar alguns dos casos atípicos de hiperplasia nodular focal e prevenir biopsias desnecessárias. Pode também desencadear uma investigação mais aprofundada de anomalias vasculares hepáticas subjacentes eventualmente desconhecidas.

Palavras-chave: Doença Hepática Induzida Quimicamente; Doenças Hepáticas; Hiperplasia Nodular Focal do Fígado; Neoplasias Hepáticas; Regeneração Hepática; Ressonância Magnética

\section{INTRODUCTION}

Apart from cirrhosis and inflammation, other liver injuries can produce different types of hepatocellular nodules. The International Working Party has classified these lesions into hyperplastic and dysplastic nodules, according to two primary sets of criteria, the cell type and the histological pattern of the surrounding liver. ${ }^{1-4}$

IHyperplastic or regenerative nodules are well-defined regions of normal liver parenchyma that have enlarged in response to a stimulus, especially from vascular origin, but also due to necrosis or other kind. 2,3,5 They are further subdivided into monoacinar or multiacinar nodules, cirrhotic regenerative nodules and focal nodular hyperplasia $(\mathrm{FNH}) .^{5}$ Multiacinar regenerative nodules (MRN), also called large regenerative nodules, are frequently grouped together

1. Imaging Department. Faculty of Medicine. University Centre Hospitals of Coimbra (CHUC). Coimbra. Portugal.

2. Department of Biomedical Imaging and Image Guided Therapy. Medical University of Vienna. General Hospital of Vienna (AKH). Vienna. Austria.

3. Pathology Department. University Centre Hospitals of Coimbra (CHUC). Coimbra. Portugal.

$\triangle$ Autor correspondente: Henrique Donato. donato.henrique@gmail.com

Recebido: 16 de janeiro de 2018 - Aceite: 18 de Junho de 2018 | Copyright @ Ordem dos Médicos 2018 
with nodular regenerative hyperplasia $(\mathrm{NRH})$, although the latter is an example of the monoacinar type, with minute micronodular transformation of a whole or part of the liver. ${ }^{1,3}$ MRN involve more than one portal tract and, attaining macroscopic dimensions (between $5 \mathrm{~mm}$ and 5 $\mathrm{cm}$ ), are easily detected on cross-sectional imaging. ${ }^{1} \mathrm{MRN}$ have been alternatively coined $\mathrm{FNH}$-like lesions, because they strongly resemble $\mathrm{FNH}$, both in imaging studies and histopathologically. ${ }^{6-8}$ They have been described in BuddChiari syndrome and other vascular liver disorders. ${ }^{2,9,10}$ An increased incidence in long time cancer survivors previously treated by chemo or radiotherapy, especially paediatric patients, has also been described, and the mechanism seems to be related to the non-selective effect of chemotherapy regimens in the non-tumorous liver. ${ }^{11-13}$ Particularly, the use of oxaliplatin-based compounds has been associated with such $\mathrm{FNH}$-like lesions. ${ }^{14}$ Disturbance of the liver microcirculation with reduced portovenous or hepatovenous flow may result in a compensatory arterial hyperperfusion, ultimately leading to a nonspecific polyclonal focal hepatocyte proliferation and MRN formation. 2,6,11,15 $^{2}$

Some authors have linked all these benign hepatocellular nodules, namely $\mathrm{NRH}, \mathrm{MRN}$ and $\mathrm{FNH}$, to a common congenital anomaly of the portal tract. ${ }^{16}$

The present study aimed to focus at the description of the key imaging features of MRN in particular those that may preclude a wrong diagnosis of simple $\mathrm{FNH}$. This distinction is clinically relevant since recognition of MRN may trigger further efforts to identify an underlying liver disease, especially of vascular origin, contrarily to the diagnosis of $\mathrm{FNH}$, which is considered an incidental finding in an otherwise normal liver., ${ }^{1,2,17}$ Multiplicity of lesions has been reported as suggestive of underlying vascular diseases. ${ }^{18}$ Other differences have been reported, such as T1 hyperintensity and T2 hypointensity of MRN lesions, absence of the central scar or a hypodense/intense rim. ${ }^{2,9,17,19}$ Furthermore, MRN should be differentiated from malignant liver lesions, especially metastases in the case of follow up of oncologic patients. ${ }^{14,15}$

\section{MATERIAL AND METHODS}

Patient selection and standard of reference

From the medical records of two large tertiary care hospitals, a search was conducted from the years 2008 to 2016. Cases containing the diagnosis of $\mathrm{FNH}$ and/or regenerative hyperplasia in the radiological report were retrieved. The database contained 26 cases of liver nodules reported as $\mathrm{FNH}$-like in patients with an underlying liver disease (Table 1). Twenty-five consecutive cases of FNH in an otherwise healthy liver were included for comparative purposes. Diagnosis of MRN and $\mathrm{FNH}$ was established by histological analysis ( $n=13$ and $n=6$, respectively) or by imaging criteria ( $n=13$ and $n=19$, respectively). Histological analysis was performed by percutaneous biopsy ( $n=8$ cases of MRN and $n=3$ cases of $F N H$ ), surgical biopsy ( $n=$ 1 case of MRN) or surgical specimen analysis ( $n=4$ cases of MRN, $n=3$ cases of $F N H$ ), according to established criteria. Imaging criteria for the diagnosis of MRN consisted in the demonstration of a FNH-like nodule on MR imaging, showing temporal stability (minimum follow-up time of two years) and exclusively detected in the clinical context of a known underlying liver disease. A FNH diagnosis was made in all cases where the typical FNH MR imaging criteria were found in an otherwise healthy patient. These include: lesion homogeneity except for the central scar; slightly different signal from the liver parenchyma on T1 and T2 sequences; strong homogeneous arterial enhancement becoming similar to the liver on the portal and delayed phases after contrast; presence of a central scar which is hypointense on pre-contrast $\mathrm{T} 1$, hyperintense on $\mathrm{T} 2$ and enhancing in the delayed phase; lack of capsule and possible lobulated contours. An additional feature is the uptake of liver-specific contrast on the hepatobiliary phase. . $^{1820-22}$

All procedures performed were in accordance with the ethical standards of the institutional research committees and with the 1964 Helsinki declaration and its later amendments or comparable ethical standards. Due to the retrospective nature of this study, with pre-existing data, formal informed consent was not required.

\section{Image analysis}

Two experienced radiologists at each centre (with more

Table 1 - Etiology groups of multiacinar regenerative nodules

\begin{tabular}{llc}
\hline Etiology group & Background condition & Number of cases \\
\hline Sinusoidal obstruction & Chemotherapy & $12(46 \%)$ \\
Non-cirrhotic portal hypertension & Idiopathic & $5(19 \%)$ \\
& Cystic fibrosis / Lung transplantation & $2(8 \%)$ \\
& Multicentric Castleman disease & 1 \\
& Non-cirrhotic liver septal fibrosis & 1 \\
Vascular malformation & Portal thrombosis & 1 \\
& Abernethy type 1b & 1 \\
Sinusoidal distension & Abernethy type 2 & 1 \\
Ischemic liver injury & Diffuse epithelioid liver granulomata (unspecific) & 1 \\
Total & Liver transplant & 1 \\
\hline
\end{tabular}


than 10 years of abdominal sub-speciality practice), blinded to the diagnosis and clinical history, performed a consensus reading of the MR exams. Only one lesion per case, the largest one that could be depicted alone, was evaluated.

MR examinations were performed according to the institutions' protocols using two magnet field strengths of 1.5 and $3 \mathrm{~T}$ and multichannel phased-array coils. All studies included gradient-echo (GRE) in/opposed phase T1-weighted (T1-w) (TR $100 \mathrm{~ms}$, TE 2.27 and $5.19 \mathrm{~ms}$, flip angle $70^{\circ}$, matrix $256 \times 192$, FOV $380 \mathrm{~mm}$, slice thickness 8 $\mathrm{mm}$ for $1.5 \mathrm{~T}$; TR $4.36 \mathrm{~ms}$, TE 1.32 and $2.46 \mathrm{~ms}$, flip angle $9^{\circ}$, matrix $320 \times 224$, FOV $380 \mathrm{~mm}$, slice thickness $4 \mathrm{~mm}$ for 3T) and fast spin-echo fat saturated (FS) T2-w sequences (TR 1550 ms, TE 93 ms, flip angle 150', matrix 384×269, FOV $380 \mathrm{~mm}$, slice thickness $8 \mathrm{~mm}$ for 1.5T; TR $5700 \mathrm{~ms}$, TE $88 \mathrm{~ms}$, flip angle $150^{\circ}$, matrix $320 \times 300$, FOV $380 \mathrm{~mm}$, slice thickness $5 \mathrm{~mm}$ for $3 \mathrm{~T}$ ), as well as 3D GRE FS T1-w sequences (TR $4.88 \mathrm{~ms}$, TE $2.38 \mathrm{~ms}$, flip angle $10^{\circ}$, matrix 256x205, FOV $380 \mathrm{~mm}$, slice thickness $3 \mathrm{~mm}$ for 1.5T; TR $3.78 \mathrm{~ms}$, TE $1.38 \mathrm{~ms}$, flip angle $11^{\circ}$, matrix $320 \times 168$, FOV $400 \mathrm{~mm}$, slice thickness $2.5 \mathrm{~mm}$ for 3T) for contrastenhanced (CE) MR after the intravenous bolus injection of extracellular gadolinium chelates or hepatobiliary chelates (Gd-EOB-DTPA, gadoxetic acid) in the late arterial phase, portal venous phase, late venous/ transitional phase (180 s after injection) and hepatobiliary phase (20 min after injection). Diffusion weighted imaging (DWI) with at least two b values $(50-150,600-800 \mathrm{~s} / \mathrm{mm} 2)$ was available in most studies ( 24 cases of $\mathrm{FNH}$ and 17 cases of MRN) (TR $2300 \mathrm{~ms}$, TE $70 \mathrm{~ms}$, flip angle $90^{\circ}$, matrix 160x120, FOV $450 \mathrm{~mm}$, slice thickness $8 \mathrm{~mm}$ for $1.5 \mathrm{~T}$; TR $6276 \mathrm{~ms}$, TE $68 \mathrm{~ms}$, flip angle $90^{\circ}$, matrix $142 \times 112$, FOV $380 \mathrm{~mm}$, slice thickness $6 \mathrm{~mm}$ for 3T).

Lesion size, shape (round/oval/lobulated), margins (well/ill-defined), structure (homogeneous/heterogeneous), presence of microscopic or macroscopic fatty content, haemorrhage and/or necrosis were recorded and analysed. T1 and T2 signal intensity (SI) and qualitative evaluation of diffusion-weighted imaging (presence/absence of restriction to diffusion) were registered. In the CE-MR study, lesions were classified according to their relative intensity to the surrounding liver parenchyma observed in the late arterial, portal and delayed/transitional phase after injection of extra-cellular Gd-chelates or gadoxetic acid, respectively. Uptake of the hepatobiliary contrast agent (gadoxetic acid) was considered to be present in cases of complete or partial nodular iso/hyperintensity compared to the liver parenchyma (22 cases of FNH and 18 cases of MRN). Detection of a hypoenhancing peripheral rim and central scar were also registered.
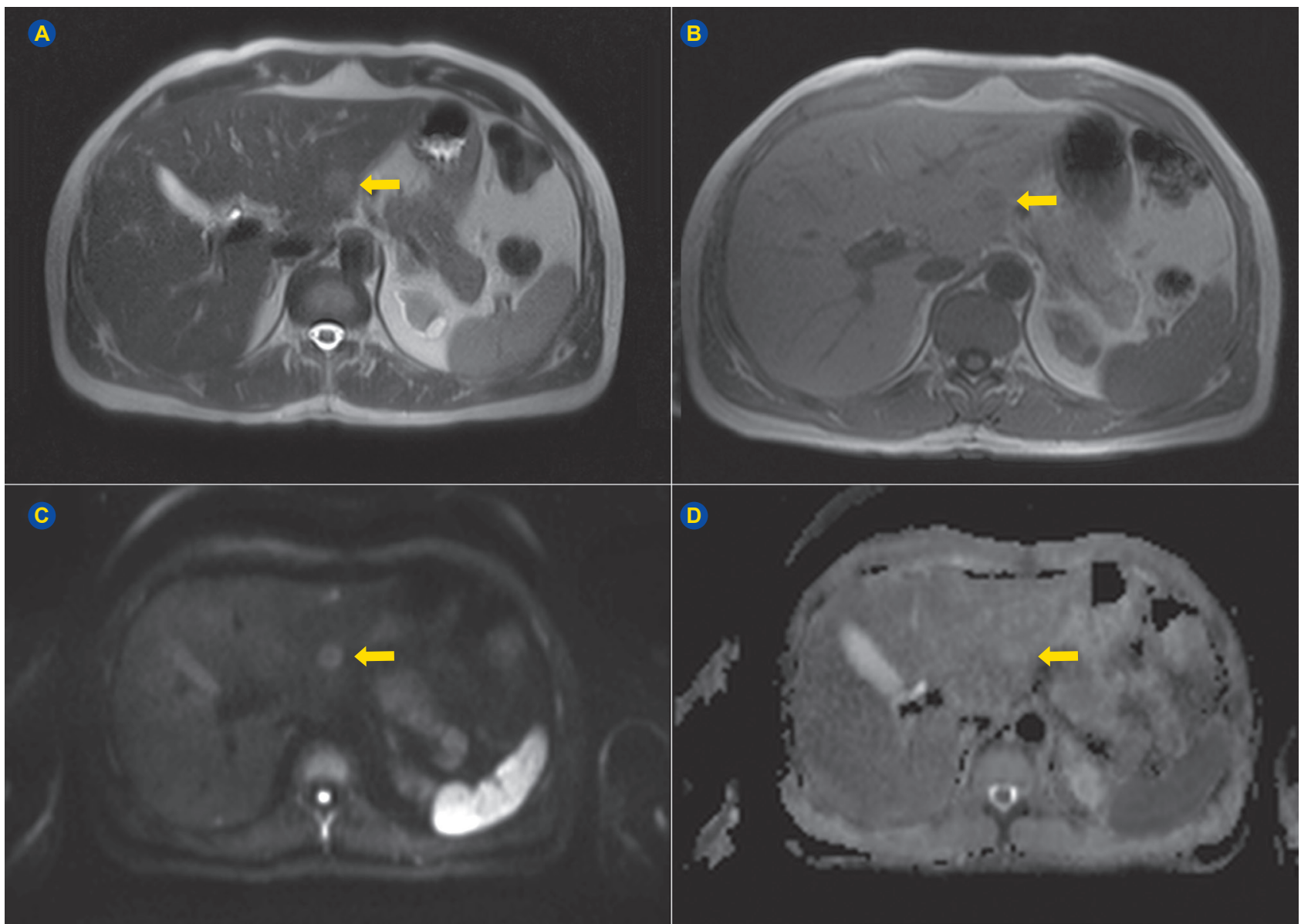

Figure 1 - Typical MR findings of MRN in a case developing after chemotherapy for rectal cancer. (A) The lesion (arrow), located in the left liver lobe, is slightly hyperintense on the T2-w HASTE sequence. (B) The lesion is hypointense in the in-phase GRE T1-w image. (C and D) There is no restriction in the $\mathrm{b} 700 \mathrm{DWI}(\mathrm{C})$ and ADC map (D). 

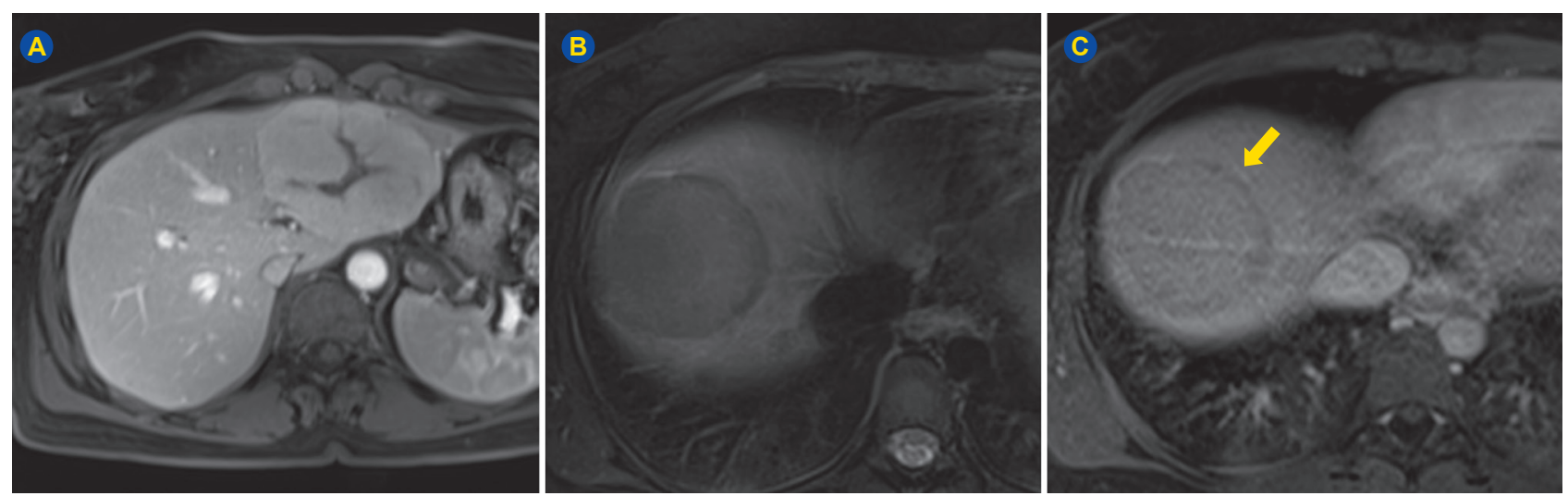

Figure 2 - Assessment of the typical central scar of FNH in MRN. (A) CE-MR in the late arterial phase showing a FNH in an otherwise healthy liver displaying the typical central scar. (B) T2-w FS sequence in a case of Abernethy malformation showing a large MRN in the right liver lobe. Despite its size the nodule does not show a T2 hyperintense central scar. (C) CE-MR in the delayed venous phase of the same case in B showing also no late enhancing central scar but displaying a hypointense rim (arrow).
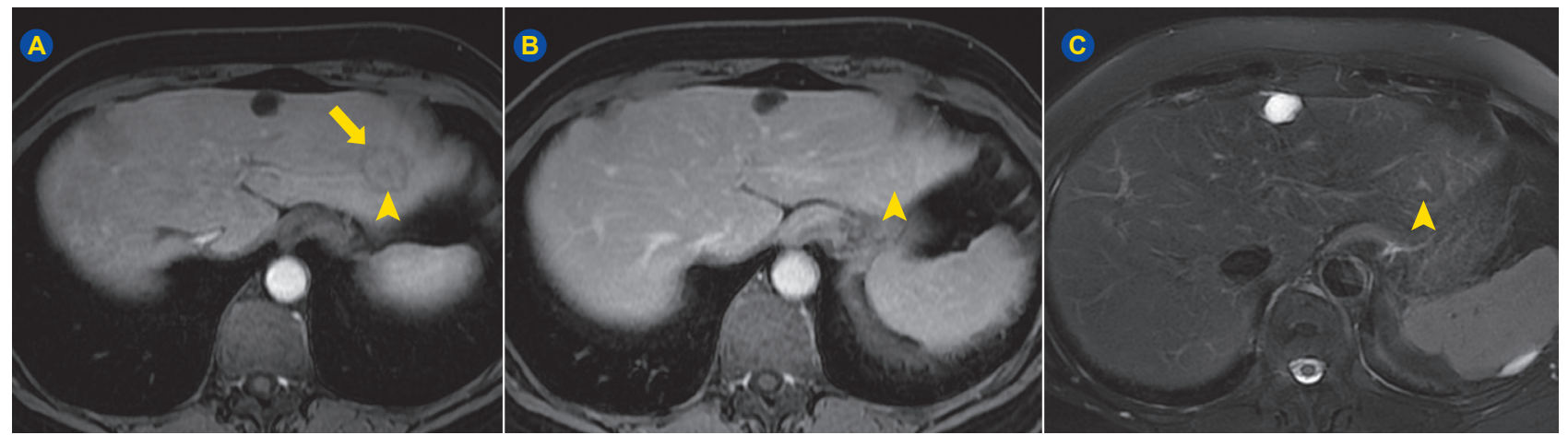

Figure 3 - Assessment of the hypointense rim in MRN. (A) CE-MR in the late arterial phase after extracellular Gd administration in a postchemotherapy patient. There is a MRN lesion in the left lobe with a distinct hypointense rim (arrow). Note that the lesion also has a central scar (arrowhead). (B) CE-MR in the late venous phase of the same patient. The central scar is similar to FNH with late enhancement (arrowhead). (C) T2-w FS sequence of the same patient. The central scar has typical T2 hyperintensity. A simple hepatic cyst is also included in the images.

\section{Statistical analysis}

The median size of MRN and FNH lesions in the imaging exams was calculated together with the interquartile range (IQR). Also, in the MRN subgroup developing after chemotherapy, the median time from the start of the treatment to the time of detection by imaging exams was determined. Comparative analysis between the MRN group and the $\mathrm{FNH}$ group were performed with SPSS v.20. Comparison of the continuous variable dimension between both groups was conducted using Mann-Whitney $U$ test and comparison of categorical variables between both groups was conducted using Fisher's exact test. In categorical variables with three values, characteristics were grouped together for comparison, according to the previously described imaging characteristics of MRN: T1-w SI features were grouped as hyperintense versus non-hyperintense (iso/hypointense); T2-w SI as hypointense versus non-hypointense (iso/ hyperintense); CE-MR evaluation as hyperenhancing versus non-hyperenhancing (iso/hypoenhancing) in the late arterial phase and as washout positive (hypoenhancing) or washout negative (iso/hyperenhancing) in the portal phase. Statistical significance was considered for a $p$ value $<0.05$.

\section{RESULTS}

Twelve cases of MRN were detected in postchemotherapy patients. The time from the start of the treatment to the diagnosis was registered in nine cases, corresponding to a median of 5 years (IQR: 9 ).

Of the remaining 14 cases of MRN, 10 were detected in the context of non-cirrhotic portal hypertension and two in patients with vascular malformations (Table 1).

The median size of FNH lesions was $6.00 \mathrm{~cm}$ (IQR: 5.20 ) while the median size of MRN was $2.35 \mathrm{~cm}$ (IQR: 2.13), which was significantly smaller $(U=98.50, p<0.001)$. The majority of lesions in both groups were round or oval, with well-defined borders and homogeneous structure. None of the FNH lesions displayed haemorrhage or necrosis. Only one case of MRN showed evidence of partial necrosis but none had evidence of haemorrhage. Regarding T1-w SI, two (8\%) FNH lesions showed T1 hyperintensity, (including one with microscopic fat content determined by MR), contrarily to five MRN (19\%), however the association between T1 hyperintensity and the type of nodule was not significant. None of the T1-w hyperintense MRN had macroscopic or microscopic fat components. T2-w SI analysis showed that the majority of $\mathrm{FNH}$ and MRN were hyper to isointense but 
six MRN lesions and one FNH disclosed T2-w hypointensity, but the relation was not significant ( $p=0.099$; Fig.1). DWI was performed in 24 cases of FNH and 17 cases of MRN. None of the FNH lesions showed diffusion restriction and only three MRN had DWI restriction $(p=0.064)$.

CE-MR was performed in all patients and there was no association between the type of liver nodule and presence of hyperintensity in the late arterial phase or washout in the

Table 2 - Imaging findings of focal nodular hyperplasia and multiacinar regenerative nodules with comparative analysis

\begin{tabular}{|c|c|c|c|}
\hline Feature & $\begin{array}{c}\text { FNH } \\
(n=25)\end{array}$ & $\begin{array}{c}\text { MRN } \\
(n=26)\end{array}$ & $p$ value \\
\hline $\begin{array}{l}\text { Size } \\
\text { (median) }\end{array}$ & $\begin{array}{l}6.00 \mathrm{~cm} \\
\text { (IQR: } 5.20)\end{array}$ & $\begin{array}{c}2.35 \mathrm{~cm} \\
\text { (IQR: } 2.13)\end{array}$ & $<0.001^{*, \S}$ \\
\hline $\begin{array}{l}\text { Shape } \\
\text { round/oval } \\
\text { lobulated }\end{array}$ & $\begin{array}{c}22 / 25(88 \%) \\
3 / 25(12 \%)\end{array}$ & $\begin{array}{c}23 / 26(88 \%) \\
3 / 26(12 \%)\end{array}$ & $1.000 \pi$ \\
\hline $\begin{array}{l}\text { Borders } \\
\text { well defined } \\
\text { ill defined }\end{array}$ & $\begin{array}{c}24 / 25(96 \%) \\
1 / 25\end{array}$ & $\begin{array}{c}26 / 26(100 \%) \\
0 / 26\end{array}$ & $0.490 \pi$ \\
\hline $\begin{array}{l}\text { Structure } \\
\text { homogeneous } \\
\text { heterogeneous }\end{array}$ & $\begin{array}{l}16 / 25(64 \%) \\
9 / 25(36 \%)\end{array}$ & $\begin{array}{c}23 / 26(88 \%) \\
3 / 26(12 \%)\end{array}$ & $0.052^{\pi}$ \\
\hline $\begin{array}{l}\text { T1-w SI } \\
\text { hypo } \\
\text { iso } \\
\text { hyper }\end{array}$ & $\begin{array}{c}10 / 25(40 \%) \\
13 / 25(52 \%) \\
2 / 25(8 \%)\end{array}$ & $\begin{array}{c}7 / 26(27 \%) \\
14 / 26(54 \%) \\
5 / 26(19 \%)\end{array}$ & $0.419^{\pi}$ \\
\hline $\begin{array}{l}\text { T2-w SI } \\
\text { hypo } \\
\text { iso } \\
\text { hyper }\end{array}$ & $\begin{array}{c}1 / 25 \\
11 / 25(44 \%) \\
13 / 25(52 \%)\end{array}$ & $\begin{array}{c}6 / 26(23 \%) \\
10 / 26(38 \%) \\
10 / 26(38 \%)\end{array}$ & $0.099^{\pi}$ \\
\hline $\begin{array}{l}\text { DWI } \\
\text { restriction } \\
\text { w/o restriction }\end{array}$ & $\begin{array}{c}0 / 24 \\
24 / 24(100 \%)\end{array}$ & $\begin{array}{c}3 / 17(18 \%) \\
14 / 17(82 \%)\end{array}$ & $0.064 \pi$ \\
\hline $\begin{array}{l}\text { Late arterial phase } \\
\text { hypoenhancing } \\
\text { isoenhancing } \\
\text { hyperenhancing }\end{array}$ & $\begin{array}{c}0 / 25 \\
0 / 25 \\
25 / 25(100 \%)\end{array}$ & $\begin{array}{c}0 / 26 \\
5 / 26(19 \%) \\
21 / 26(81 \%)\end{array}$ & $0.051 \pi$ \\
\hline $\begin{array}{l}\text { Portal venous phase } \\
\text { hypoenhancing } \\
\text { isoenhancing } \\
\text { hyperenhancing }\end{array}$ & $\begin{array}{c}1 / 25 \\
16 / 25(64 \%) \\
8 / 25(32 \%)\end{array}$ & $\begin{array}{c}2 / 26(8 \%) \\
11 / 26(42 \%) \\
13 / 26(50 \%)\end{array}$ & $1.000^{\pi}$ \\
\hline $\begin{array}{l}\text { Delayed phase } \\
\text { hypoenhancing } \\
\text { isoenhancing } \\
\text { hyperenhancing }\end{array}$ & $\begin{array}{c}0 / 25 \\
16 / 25(64 \%) \\
9 / 25(36 \%)\end{array}$ & $\begin{array}{c}2 / 26(8 \%) \\
10 / 26(38 \%) \\
14 / 26(54 \%)\end{array}$ & $0.490^{\pi}$ \\
\hline $\begin{array}{l}\text { Hepatobiliary phase } \\
\text { contrast uptake }\end{array}$ & $22 / 22(100 \%)$ & $18 / 18(100 \%)$ & - \\
\hline $\begin{array}{l}\text { Hypoenhancing rim } \\
\text { present }\end{array}$ & $2 / 25(8 \%)$ & $9 / 26(35 \%)$ & $0.038^{*}, \pi$ \\
\hline $\begin{array}{l}\text { Central scar } \\
\text { present }\end{array}$ & $20 / 25(80 \%)$ & $9 / 26(35 \%)$ & $0.002^{*, \pi}$ \\
\hline
\end{tabular}

FNH: focal nodular hyperplasia; MRN: multiacinar regenerative nodules; IQR: interquartile range; T1-w SI: T1-weighted signal intensity; T2-w SI: T2-weighted signal intensity; DWI: diffusion weighted imaging; w/o: without; * with statistical significance $(p<0.05) ;{ }^{\S}$ comparison performed with Mann-Whitney U test; " 
portal and/or delayed phases. The majority of lesions in both groups $(\mathrm{FNH}=25 ; \mathrm{MRN}=21)$ were hypervascular in the late arterial phase without washout in the portal phase. In cases where gadoxetic acid was administered (22 FNH and 18 MRN cases) contrast uptake (considered equal or higher than the adjacent normal parenchyma in the hepatobiliary phase) was seen at a similar visual rate.

The association between the presence of a hypointense rim and the type of nodule, MRN or $\mathrm{FNH}$, was significant as was the relation with the presence of a central scar ( $p=0.038$ and $p=0.002$, respectively). Readers were able to detect a hypointense rim at the CE-MR in nine MRN and two FNH lesions, and a central scar in $20 \mathrm{FNH}$ lesions $(80 \%)$ and nine MRN lesions (35\%) (Fig's. 2 and 3).

The complete data of imaging characteristics in both types of nodules is summarized in Table 2.

\section{DISCUSSION}

Although MRN is a benign hepatocellular nodule resembling $\mathrm{FNH}$, the fact that MRN is linked to a potential vascular underlying abnormality of the liver makes its recognition clinically important, since further diagnostic work-up may take place. Also, when dealing with other clinical contexts such as cirrhosis or chemotherapy-treated patients, the differentiation from malignancy assumes special importance if one considers that it may appear as a "de novo" focal liver lesion on follow-up imaging studies. $^{2,14,15,17}$ Our study has shown that, among all MR imaging features, there are two important differences for the discrimination between MRN and $\mathrm{FNH}$ : the presence of a central scar and of a hypointense peripheral rim detected at the contrast-enhanced study. MRN generally lack a central scar while this feature is shown on $80 \%$ of $\mathrm{FNH}$, the reported MRI central scar detection rate. ${ }^{20}$ Since MRN tended to be significantly smaller than $\mathrm{FNH}$, this could explain the difference in the detection rate of the central scar but it should also be stressed that even larger MRN may not display this imaging feature.6,9,22-24 The presence of a hypoenhancing rim is an important distinctive finding, present in $35 \%$ of MRN against only $8 \%$ of $\mathrm{FNH}$. Also coined the halo sign, correlation with the pathological specimen, has showed the presence of peripheral sinusoidal dilatation and vascular congestion in the peri-nodular, atrophic and compressed parenchyma. 2,19,25,26 Unfortunately, this interesting feature was only seen in less than half the cases of MRN, thus reducing its usefulness for the differential diagnosis between the two lesion types based on imaging alone.

These features may explain some cases of atypical FNH that occasionally lead to unnecessary invasive procedures to secure a diagnosis, such as biopsy or even liver resection, as displayed in this series.

Otherwise, like typical $\mathrm{FNH}, \mathrm{MRN}$ are generally well-defined homogeneous nodules, without evidence of calcification, haemorrhage or necrosis., ${ }^{9,22}$ Although MRN were initially reported as having high T1-w SI and low to intermediate $\mathrm{T} 2-\mathrm{W} \mathrm{SI}$, there were no significant associations regarding $\mathrm{SI}$ in the current study. MRN were mostly $\mathrm{T} 1-\mathrm{w}$ isointense and T2-w iso-hyperintense. 1,2,9,25 $^{-1}$ It has been reported that the MRN T1-w hyperintensity may be relative, due to the hypointensity of a surrounding abnormally congested liver. ${ }^{6}$ We note, however, that in the present series there was no pathologic proof of liver congestion in the non-tumoural parenchyma. Other possible explanation for the T1-w hyperintense MRN is the presence of paramagnetic substances, such as copper. ${ }^{1,2}$ On the other hand, FNH T1-w hyperintensity may result from fatty replacement, one of the most common atypical findings reported for this entity. ${ }^{20}$ As expected, DWI does not play a significant role in the differentiation of the two types of hepatocellular nodules. The SI of both FNH and MRN seen on high b-value DWI were furthermore similar to the surrounding liver parenchyma. ${ }^{27-29}$

Concerning the CE-MR study, both categories of nodules behave similarly with brisk transitory enhancement in the late arterial phase and a predominant lack of washout in the subsequent phases. The hypervascular behaviour reflecting its increased arterial supply may be problematic for the distinction between MRN and HCC in the context of cirrhosis or, more rarely, with hypervascular liver metastases in the setting of oncologic follow-up. 2,4,14,15,30 Therefore, it is important to acknowledge the absence of washout in order to reinforce their benign origin, avoiding erroneous patient management. ${ }^{2,11,17,31}$ The absence of a correlate of this hypervascular lesion on the DWI is again in favour of MRN and against metastasis. ${ }^{32,33}$

As expected, all FNH and MRN nodules in our series showed contrast uptake in the hepatobiliary phase after gadoxetic acid administration similar or higher than the surrounding liver. This reflects their benign hepatocellular origin with preservation of the active membrane transport system via the surface receptors OATPB1/3, a feature that allows prompt discrimination from poorly differentiated HCC and liver metastases. . $^{2,34}$

This study has several limitations: the small number of patients, although fairly equivalent between both groups, may have affected the statistical significance of some comparisons. However, many studies in the literature have a similar number of cases of this infrequent type of liver nodule..$^{1,2,9,30}$ Only one lesion per patient, considered the dominant lesion, was chosen, which implies the non-verified assumption of an equal behaviour among the multiple nodules in the same patient; not all cases were histologically proved especially among the MRN group. As previously explained the combination of imaging signs, together with the late uptake of hepatocyte-specific contrast agent in the specific clinical context of a non-healthy liver was used as an imperfect standard of reference., ${ }^{9,23,30}$ Furthermore, the retrospective nature of the study did not allow verification of the real clinical usefulness concerning different choices for patient management.

Most published studies regarding MRN have focused on the distinction with malignant liver lesions occurring in the same clinical context. Comparison between MRN and FNH 
has not been sufficiently addressed due to the assumed immediate distinction by the different context. However this information is not always available or even known and further investigation could be prompt by the diagnosis of MRN.

Larger studies should be performed to further establish the imaging differences between these very similar benign liver lesions but with very distinct clinical implications.

\section{CONCLUSION}

Recognition of the imaging findings of MRN, namely lack of a central scar and the detection of a peripheral rim after contrast, can explain some of the atypical cases of $\mathrm{FNH}$, avoiding unnecessary invasive procedures such as biopsy or even liver resection. It may also be a trigger to investigate a previously unsuspected underlying vascular liver disease.

\section{REFERENCES}

1. Ames JT, Federle MP, Chopra K. Distinguishing clinical and imaging features of nodular regenerative hyperplasia and large regenerative nodules of the liver. Clin Radiol. 2009;64:1190-5.

2. Brancatelli G, Federle MP, Grazioli L, Golfieri R, Lencioni R. Original report Budd-Chiari syndrome and other vascular disorders of the liver: CT and MR imaging findings with clinicopathologic correlation. AJR Am J Roentgenol. 2002;178:877-83.

3. Kobayashi S, Matsui O, Gabata T, Sanada J, Koda W, Minami T, et al. Radiological and histopathological manifestations of hepatocellular nodular lesions concomitant with various congenital and acquired hepatic hemodynamic abnormalities. Jpn J Radiol. 2009;27:53-68.

4. Renzulli M, Lucidi V, Mosconi C, Quarneti C, Giampalma E, Golfieri $R$. Large regenerative nodules in a patient with Budd-Chiari syndrome after TIPS positioning while on the liver transplantation list diagnosed by Gd-EOB-DTPA MRI. Hepatobiliary Pancreat Dis Int. 2011;10:439 42.

5. Hussain SM, Zondervan PE, Schalm SW, De Man RA, Krestin GP. Benign versus malignant hepatic nodules: MR imaging findings with pathologic correlation. Radiographics. 2002;22:1023-36.

6. Maetani Y, Itoh K, Egawa H, Haga H, Sakurai T, Nishida N, et al. Benign hepatic nodules in Budd-Chiari syndrome: radiologic-pathologic correlation with emphasis on the central scar. AJR Am J Roentgenol. 2002;178:869-75.

7. DeLeve LD, Valla DC, Garcia-Tsao G. American Association for the Study Liver Diseases Vascular disorders of the liver. Hepatology. 2009;49:1729-64.

8. Choi JY, Lee HC, Yim JH, Shim JH, Lim YS, Shin YM, et al. Focal nodular hyperplasia or focal nodular hyperplasia-like lesions of the liver: a special emphasis on diagnosis. J Gastroenterol Hepatol. 2011;26:1004-9

9. Marin D, Galluzzo A, Plessier A, Brancatelli G, Valla D, Vilgrain V. Focal nodular hyperplasia-like lesions in patients with cavernous transformation of the portal vein: prevalence, MR findings and natural history. Eur Radiol. 2011;21:2074-82.

10. Wells ML, Fenstad ER, Poterucha JT, Hough DM, Young PM, Araoz PA, et al. Imaging findings of congestive hepatopathy. Radiographics. 2016;36:1024-37.

11. De Pasquale MD, Monti L, D'Andrea ML, De loris MA, Castellano A. Focal nodular hyperplasia and hepatic regenerating nodules in pediatric oncology patients: how much invasive approach is necessary? Ann Hepatol. 2013;12:308-14.

12. Van Den Broek MA, Damink SW, Driessen A, Dejong $\mathrm{CH}$, Bemelmans $\mathrm{MH}$. Nodular regenerative hyperplasia secondary to neoadjuvant chemotherapy for colorectal liver metastases. Case Rep Med. 2009;2009:457975.

13. Wicherts DA, de Haas RJ, Sebagh M, Ciacio O, Lévi F, Paule B, et al. Regenerative nodular hyperplasia of the liver related to chemotherapy: impact on outcome of liver surgery for colorectal metastases. Ann Surg Oncol. 2011;18:659-69.

\section{PROTECTION OF HUMAN AND ANIMAL SUBJECTS}

The authors declare that the research procedures were performed according to the regulations of the institution's ethics committee and the Code of Ethics of the World Medical Association (Declaration of Helsinki).

\section{CONFIDENTIALITY OF DATA}

The authors declare that they have followed the protocols of their work centre regarding the publication of data from patients.

\section{CONFLICT OF INTEREST}

No conflict of interest has been declared by any author.

\section{FUNDING}

No financial support was received by any author.

14. Donadon M, Di Tommaso L, Roncalli M, Torzilli G. Multiple focal nodular hyperplasias induced by oxaliplatin-based chemotherapy. World J Hepatol. 2013;5:340-4.

15. Newerla C, Schaeffer F, Terracciano L, Hohmann J. Multiple FNHlike lesions in a patient with chronic Budd-Chiari syndrome: GdEOB-enhanced MRI and BR1 CEUS findings. Case Rep Radiol. 2012;2012:685486.

16. Ueda T, Starkey J, Mori K, Fukunaga K, Shimofusa R, Motoori K, et al. A pictorial review of benign hepatocellular nodular lesions: comprehensive radiological assessment incorporating the concept of anomalous portal tract syndrome. J Hepatobiliary Pancreat Sci. 2011;18:386-96.

17. Zhang R, Qin S, Zhou Y, Song Y, Sun L. Comparison of imaging characteristics between hepatic benign regenerative nodules and hepatocellular carcinomas associated with Budd - Chiari syndrome by contrast enhanced ultrasound. Eur J Radiol. 2012;81:2984-9.

18. European Association for the Study of the Liver (EASL). EASL Clinical Practice Guidelines on the management of benign liver tumours. J Hepatol. 2016;65:386-98.

19. Alonso-Gamarra E, Parrón M, Pérez A, Prieto C, Hierro L, LópezSantamaría M. Clinical and radiologic manifestations of congenital extrahepatic portosystemic shunts: a comprehensive review. Radiographics. 2011;31:707-22.

20. Hussain SM, Terkivatan T, Zondervan PE, Lanjouw E, de Rave S, ljzermans JN, et al. Focal nodular hyperplasia: findings at state-ofthe-art MR imaging, US, CT, and pathologic analysis. Radiographics. 2004;24:3-17.

21. Libbrecht L, Cassiman D, Verslype C, Maleux G, Van Hees D, Pirenne $J$, et al. Clinicopathological features of focal nodular hyperplasialike nodules in 130 cirrhotic explant livers. Am J Gastroenterol. 2006;101:2341-6.

22. Ba-ssalamah A, Schima W, Schmook MT, Linnau KF, Schibany N, Helbich T, et al. Atypical focal nodular hyperplasia of the liver: imaging features of contrast agents. AJR Am J Roentgenol. 2002;179:1447-56.

23. Bartolotta TV, Taibbi A, Brancatelli G, Matranga D, Tumbarello M, Midiri $\mathrm{M}$, et al. Imaging findings of hepatic focal nodular hyperplasia in men and women: are they really different? Radiol Med. 2014;119:222-30.

24. Brancatelli G, Federle MP, Grazioli L, Blachar A, Peterson MS, Thaete L. Focal nodular hyperplasia: CT findings with emphasis on multiphasic helical CT in 78 patients. Radiology. 2001;219:61-8.

25. Buckley O, O' Brien J, Snow A, Stunell H, Lyburn I, Munk PL, et al. Imaging of Budd-Chiari syndrome. Eur Radiol. 2007;17:2071-8.

26. Wanless IR. Micronodular transformation (nodular regenerative hyperplasia) of the liver: a report of 64 cases among 2,500 autopsies and a new classification of benign hepatocellular nodules. Hepatology. 1990;11:787-97.

27. Sutherland T, Seale M, Yap K. Part 1: MRI features of focal nodular hyperplasia with an emphasis on hepatobiliary contrast agents. J Med Imaging Radiat Oncol. 2014;58:50-5. 
28. Miller FH, Hammond N, Siddiqi AJ, Shroff S, Khatri G, Wang Y, et al. Utility of diffusion-weighted MRI in distinguishing benign and malignant hepatic lesions. J Magn Reson Imaging. 2010;32:138-47.

29. Donati F, Boraschi P, Gigoni R, Salemi S, Falaschi F, Bartolozzi C. Focal nodular hyperplasia of the liver: diffusion and perfusion MRI characteristics. Magn Reson Imaging. 2013;31:10-6.

30. Vilgrain V, Lewin M, Vons C, Denys A, Valla D, Flejou JF, et al. Hepatic nodules in Budd-Chiari syndrome: imaging features. Radiology. 1999;210:443-50.

31. Kim JW, Lee CH, Kim SB, Park BN, Park YS, Lee J, et al. Washout appearance in Gd-EOB-DTPA-enhanced MR imaging: A differentiating feature between hepatocellular carcinoma with paradoxical uptake on the hepatobiliary phase and focal nodular hyperplasia-like nodules. $J$
Magn Reson Imaging. 2017:45:1599-1608.

32. Fruehwald-Pallamar $\mathrm{J}$, Bastati-Huber $\mathrm{N}$, Fakhrai $\mathrm{N}$, Jantsch $\mathrm{M}$, Puchner S, Herneth AM, et al. Confident non-invasive diagnosis of pseudolesions of the liver using diffusion-weighted imaging at 3T MRI. Eur J Radiol. 2012;81:1353-9.

33. Wei C, Tan J, Xu L, Juan L, Zhang SW, Wang L, et al. Differential diagnosis between hepatic metastases and benign focal lesions using DWI with parallel acquisition technique: a meta-analysis. Tumour Biol. 2015;36:983-90.

34. Yoneda N, Matsui O, Kitao A, Kozaka K, Kobayashi S, Sasaki M, et al. Benign hepatocellular nodules: Hepatobiliary phase of gadoxetic acid-enhanced MR imaging based on molecular background. Radiographics. 2016;36:2010-27. 